\title{
ERRATUM
}

\section{Erratum to: Do heart and respiratory rate variability improve prediction of extubation outcomes in critically ill patients?}

\author{
Andrew JE Seely ${ }^{1,2,11^{*}}$, Andrea Bravi², Christophe Herry ${ }^{1}$, Geoffrey Green ${ }^{1}$, André Longtin², Tim Ramsay ${ }^{1}$,

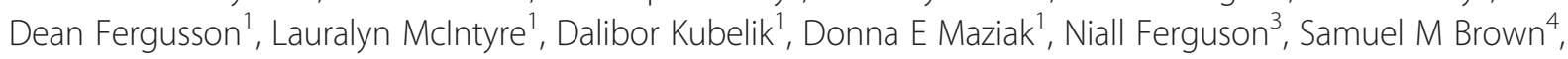 \\ Sangeeta Mehta ${ }^{5}$, Claudio Martin ${ }^{6}$, Gordon Rubenfeld ${ }^{7}$, Frank J Jacono ${ }^{8}$, Gari Clifford ${ }^{9}$, Anna Fazekas ${ }^{1}$, \\ John Marshall ${ }^{10}$ and The Canadian Critical Care Trials Group (CCCTG)
}

See related research by Seely et al., http://ccforum.com/content/18/2/R65

\section{Erratum}

While compiling this article [1] one of the authors was inadvertently omitted from the author list. This author, The Canadian Critical Care Trials Group (CCCTG), has been included in the corrected author list above.

\section{Competing interests}

Andrew Seely is Founder and Chief Science Officer of Therapeutic Monitoring Systems (TMS); TMS aims to commercialize patent-protected applications of multiorgan variability monitoring to provide variability-directed clinical decision support at the bedside to improve care for patients at risk for or with existing critical illness. Andrew Seely holds a patent jointly with co-authors Andrea Bravi and André Longtin on composite measures of variability. Geoffrey Green is Product Manager for TMS. John Marshall and Gari Clifford are on the Scientific Advisor Board of TMS. Other authors have no relevant conflict of interest to disclose.

\section{Acknowledgements}

Members of the Canadian Critical Care Trials Group (CCCTG):

Dr Jon Hooper, Tracy McArdle, Shawna Reddie, Dr Peter Wilkes, Denyse

Winch, Dr Claudio Martin, Eileen Campbell, Dr Sangeeta Mehta, Maedean

Brown, Dr Peter Dodek, Betty Jean Ashley, Dr John Marshall and Orla Smith.

\begin{abstract}
Author details
'Ottawa Hospital Research Institute, 725 Parkdale Avenue, Ottawa, ON K1Y 4E9, Canada. ${ }^{2}$ University of Ottawa, 75 Laurier Avenue East, Ottawa, ON K1N 6N5, Canada. ${ }^{3}$ University Hospital Network, University of Toronto, 190 Elizabeth Street, Toronto, ON M5G 2C4, Canada. ${ }^{4}$ Intermountain Medical Center (IMC), Shock Trauma ICU, 5121 Cottonwood Street, Murray, UT 84157, USA. ${ }^{5}$ Mt Sinai, University of Toronto, 600 University Avenue, Toronto, ON M5G 1X5, Canada. ${ }^{6}$ London Health Sciences Center, 339 Windermere Road, London, ON N6G 2V4, Canada. ' Sunnybrook Hospital, University of Toronto, 2075 Bayview Avenue, Toronto, ON M4N 3M5, Canada. ${ }^{8}$ University Hospital Case Medical Center, Case Western Reserve University, 11100 Euclid Avenue, Cleveland, OH 44106, USA. ${ }^{9}$ University of Oxford, Kellogg College, Banbury Road, Oxford OX2 6PN, United Kingdom. ${ }^{10}$ St. Michaels Hospital, University of Toronto, 30 Bond Street, Toronto, ON M5B 1W8, Canada. "'Divisions of Thoracic Surgery \& Critical Care Medicine, 501 Smyth Road, Ottawa, ON K1H 8L6, Canada.
\end{abstract}

\footnotetext{
* Correspondence: aseely@ohri.ca

'Ottawa Hospital Research Institute, 725 Parkdale Avenue, Ottawa, ON K1Y 4E9, Canada

${ }^{2}$ University of Ottawa, 75 Laurier Avenue East, Ottawa, ON K1N 6N5, Canada
}

Published online: 02 December 2014

\section{Reference}

1. Seely AJE, Bravi A, Herry C, Green G, Longtin A, Ramsay T, Fergusson D, McIntyre L, Kubelik D, Maziak DE, Ferguson N, Brown SM, Mehta S, Martin C, Rubenfeld G, Jacono FJ, Clifford G, Fazekas A, Marshall J: Do heart and respiratory rate variability improve prediction of extubation outcomes in critically ill patients? Crit Care 2014, 18:R65.

doi:10.1186/s13054-014-0620-z

Cite this article as: Seely et al:: Erratum to: Do heart and respiratory rate variability improve prediction of extubation outcomes in critically ill patients? Critical Care 2014 18:620.

\section{() Biomed Central}

(c) 2014 Seely et al.; licensee BioMed Central Ltd. The licensee has exclusive rights to distribute this article, in any medium, for 12 months following its publication. After this time, the article is available under the terms of the Creative Commons Attribution License (http://creativecommons.org/licenses/by/4.0), which permits unrestricted use, distribution, and reproduction in any medium, provided the original work is properly credited. The Creative Commons Public Domain Dedication waiver (http:// creativecommons.org/publicdomain/zero/1.0/) applies to the data made available in this article, unless otherwise stated. 